\title{
ENHANCED REMOVAL OF PERSISTENT CONTAMINANTS AND TOXICITY REDUCTION THROUGH THE APPLICATION OF A TRIPLE-STAGE FENTON PROCESS TO SANITARY LANDFILL LEACHATES FROM YUCATAN, MEXICO
}

\author{
Ana M. Escalante-Mañéa , Roger I. Méndez-Noveloa ${ }^{a}$ Germán Giácoman-Vallejos ${ }^{\mathrm{a}}$, Avel A. González-Sánchez ${ }^{\mathrm{a}}$, Jéssica \\ Romo-Alvarado $^{\mathrm{b}}$, Reyna C. Collí-Duláb, ${ }^{\mathrm{b}, \mathrm{C}}$ Carlos A. Quintal-Franco and Carlos Puch-Hau ${ }^{\mathrm{b}, *, \mathbb{C}}$ \\ ${ }^{a}$ Facultad de Ingeniería, Universidad Autónoma de Yucatán, Mérida, Yucatán, México \\ bDepartamento de Recursos del Mar, Centro de Investigación y de Estudios Avanzados del Instituto Politécnico Nacional, 97310, \\ Mérida, Yucatán, México \\ ${ }^{\mathrm{c} C o n s e j o ~ N a c i o n a l ~ d e ~ C i e n c i a ~ y ~ T e c n o l o g i ́ a, ~ C i u d a d ~ d e ~ M e ́ x i c o, ~ M e ́ x i c o ~}$
}

Recebido em 20/10/2021; aceito em 17/12/2021; publicado na web em 16/02/2022

\begin{abstract}
Sanitary landfill leachate (SLL) is a mixture of highly toxic and recalcitrant pollutants that threatens the water quality of the Yucatán Peninsula karst aquifer, one of the most extensive aquifers on the planet. To reduce the adverse environmental impacts of this wastewater, a triple-stage Fenton process (FP) was applied in an old SLL. Removal efficiencies were evaluated in terms of physicochemical variables, metal(oid)s concentrations, mass spectrometric identification of organic compounds and Daphnia magna acute toxicity test. The triple-stage FP achieved an $88 \%$ chemical oxygen demand (COD) removal, representing an improvement of $13 \%$ compared to FP performed in a single stage. Further, metal(oid)s such as aluminum, arsenic, chromium, nickel and zinc as well as organic compounds were substantially reduced. With respect to acute toxicity, the treatment produced a $64 \%$ reduction. Thus, this treatment system seems to be an effective option to reduce the dangerous level of SLL.
\end{abstract}

Keywords: solid waste; pollutants; Fenton oxidation; ecotoxicity; karst aquifer.

\section{INTRODUCTION}

The Yucatan Peninsula karst aquifer system extends over an area of approximately $165,000 \mathrm{~km}^{2}$ in Mexico, Guatemala, and Belize; it is one of the most extensive aquifers in the world. ${ }^{1,2}$ Unfortunately, karstic aquifers are highly vulnerable to contamination from anthropogenic sources. In this regard, groundwater quality could be adversely affected by dumping of municipal solid waste.

Landfilling is the predominant method for managing municipal solid wastes (MSW). Liquids resulting from the release of water in the decomposition of MSW and the percolation of precipitation water through the waste layers produce sanitary landfill leachate (SLL). The SLL composition depends on different factors such as landfill age and type of waste. In general, the SLL composition contains variable concentrations of pollutants: inorganic macrocomponents (e.g. $\mathrm{Ca}^{2+}, \mathrm{Mg}^{2+}, \mathrm{Na}^{+}, \mathrm{K}^{+}, \mathrm{NH}_{4}^{+}, \mathrm{Fe}^{2+}$ and $\mathrm{Cl}^{-}$), heavy metals (e.g. $\mathrm{Cd}^{2+}, \mathrm{Cr}^{3+}, \mathrm{Cu}^{2+}, \mathrm{Pb}^{2+}, \mathrm{Ni}^{2+}$ and $\mathrm{Zn}^{2+}$ ), dissolved organic matter (e.g. volatile fatty acids and more refractory compounds such as fulvic and humic acids) and xenobiotic organic compounds (e.g. aromatic hydrocarbons, phenols, chlorinated aliphatics, pesticides and plasticizers). ${ }^{3,4}$ This complex mixture of contaminants poses a toxicological risk to groundwater when there is not an adequate treatment because it has been demonstrated that leachate leakage risk increases over time. ${ }^{5}$ Therefore, the development of appropriate treatments and the evaluation of their detoxification efficiencies on SLL are key for the protection of environmental quality.

Many methods have been used for the treatment of SLL. In general, SLL treatment technologies can be divided into three major groups: biological processes (aerobic or anaerobic); physical and chemical processes; and a combination of biological and physicochemical processes. Along with physicochemical processes such as ultrafiltration or adsorption on activated carbon, advanced

*e-mail: cashi026@hotmail.com; Carlos.Puch@cinvestav.mx oxidation processes (AOPs) are feasible choices to eliminate pollutants. ${ }^{6}$ Among AOPs, Fenton process (FP) is applicable for the treatment of non-biodegradable/highly toxic SLL where biological processes have very limited effectiveness. ${ }^{3} \mathrm{FP}$ is a simple, cost effective and eco-friendly method since it does not require electric energy/UV lamp/ultrasonic device.$^{7,8} \mathrm{FP}$ can be used as pretreatment method to biological process or post treatment to reduce the organic content to the desired level. ${ }^{89}$ Oxidizing agents in this method are free radicals, with hydroxyl radicals being the most important. Hydroxyl radicals are generated during reaction of ferrous iron $\left(\mathrm{Fe}^{2+}\right)$ with hydrogen peroxide $\left(\mathrm{H}_{2} \mathrm{O}_{2}\right)$. Hydroxyl radicals are extremely reactive, with an oxidation potential of $2.80 \mathrm{~V}$, and they can virtually oxidize/ mineralize a wide range of organic compounds to carbon dioxide and water. If the concentrations of reactants are not limiting, the organics can be completely mineralized by radical addition, hydrogen abstraction, electron transfer and radical combination; ${ }^{10}$ however, several operating conditions may influence FP efficiency such as the reagent addition mode. Generally, Fenton reagents are added to SLL in a single step; such addition may cause self-decomposition of $\mathrm{H}_{2} \mathrm{O}_{2}$ due to high localized concentrations at the point of injection, and subsequent scavenging of hydroxyl radicals by a large amount of $\mathrm{H}_{2} \mathrm{O}_{2}$. A possible alternative to improve $\mathrm{FP}$ is the successive addition of $\mathrm{Fe}^{2+}$ and $\mathrm{H}_{2} \mathrm{O}_{2}$ in multiple steps or stages, an approach that keeps the $\mathrm{Fe}^{2+}: \mathrm{H}_{2} \mathrm{O}_{2}$ molar ratio at a favorable value at every addition. Therefore, the scavenging effects could be minimized, and higher chemical oxygen demand (COD) removal efficiency could be achieved. ${ }^{11}$ In particular, Yoo et al. ${ }^{12}$ reported a COD removal efficiency with a two-step dose of reagent approximately $10 \%$ higher than that with a single dose for batch operation of SLL treatment, while Mahmud et al. ${ }^{13}$ reported a COD removal efficiency with a three-step dose of reagents approximately $11 \%$ higher than that with a single dose. Thus, to overcome FP limitation related to hydroxyl-radical generation, the application of several cycles of Fenton oxidation using a multi-stage system would increase mineralization efficiency of pollutants. 
The efficiency of the applied treatment has traditionally been evaluated based on the disappearance of primary pollutants; however, some studies do not include toxicity assessment after COD reduction, which does not mean that the water could be safe for discharge. The formation of undesirable toxic by-products due to incomplete mineralization may be more harmful than primary pollutants. ${ }^{14}$ Hence, the possible risks of the treated SLL to the environment should be evaluated through physicochemical analyses as well as toxicity bioassays. In this sense, Daphnia magna is one of the most used approach in toxicity assessment of different chemical compounds, ${ }^{15,16}$ including SLL. ${ }^{17}$ D. magna toxicity test is recommended by the Organization for Economic Co-operation and Development (OECD) in Acute Immobilization Test. ${ }^{18}$ This toxicity test has been adopted by different environmental organizations including the United States Environmental Protection Agency (USEPA), the American Society for Testing and Materials (ASTM), and the Environment Canada. ${ }^{19,20}$ D. magna provides information of the effects on the aquatic life of the effluent-receiving groundwater bodies. ${ }^{21}$

Thus, the aims of this study were to enhance the removal of SLL persistent pollutants through of the application of a triple-stage FP and to assess its detoxification efficiency using the freshwater crustacean D. magna. The site used for this study was a sanitary landfill from the city of Merida, Yucatan, Mexico, a site where the efficiency of a triple-stage FP for contaminant removal and acute leachate toxicity have not yet been reported.

\section{EXPERIMENTAL}

\section{Landfill sampling and the Fenton oxidation}

The SLL samples were collected from leachate storage basins of the sanitary landfill from Merida, Yucatan, Mexico; they were transported in high-density polyethylene containers and stored in the laboratory at $4{ }^{\circ} \mathrm{C}$.

For the FP were used the operating conditions previously established by Mendez-Novelo et al. ${ }^{22}$ in the SLL from Merida city, where optimal dose for the Fenton oxidation were previously standardized. To decrease SLL toxicity, reaction time was selected at $120 \mathrm{~min}$ according to Colombo et al..$^{23}$

All the Fenton reactions were carried out by a standard jar test apparatus (Phipps and Bird, VA, USA). Analytical-grade chemical reagents were purchased from JT Baker (Mallinckrodt Baker Inc, Edo de Mexico, Mexico). The FP was performed in three successive stages starting from raw SLL. To adjust the $\mathrm{pH}$ of the SLL (raw and treated) sodium hydroxide solution $\left(\mathrm{NaOH}, 10 \mathrm{~mol} \mathrm{~L}^{-1}\right)$ and concentrated sulfuric acid $\left(\mathrm{H}_{2} \mathrm{SO}_{4}, 95-97 \%\right.$, w/w) were used. In the first stage (Figure 1a), $2 \mathrm{~L}$ of raw SLL were taken, and their $\mathrm{pH}$ were adjusted to 4; the ratios were $\mathrm{Fe}^{2+}: \mathrm{H}_{2} \mathrm{O}_{2}=0.6$ (achieved by adding ferrous sulfate heptahydrate, $\mathrm{Fe}_{2} \mathrm{SO}_{4} \cdot 7 \mathrm{H}_{2} \mathrm{O}$ ) and COD: $\mathrm{H}_{2} \mathrm{O}_{2}=9$ (achieved by adding $\left.\mathrm{H}_{2} \mathrm{O}_{2} 30 \% \mathrm{v} / \mathrm{v}\right) .{ }^{22}$ Suitable reagents were added to the SLL and mixed rapidly for $5 \mathrm{~min}$ by $320 \mathrm{rpm}$ followed by slow mixing by 50 rpm for $115 \mathrm{~min}$. Subsequently, the SLL was filtered through GF/C glass microfiber filter membranes (Whatman LTd., Maidstone, UK) to remove solids. The parameter COD was used as a response variable. For comparative purposes, original conditions were returned after each stage: the effluent from the first stage (Figure $1 \mathrm{~b}$ ) was adjusted to $\mathrm{pH}$ 4 and Fenton reagent concentrations were newly calculated using the abovementioned ratios $\left(\mathrm{Fe}^{2+}: \mathrm{H}_{2} \mathrm{O}_{2}=0.6\right.$ and COD: $\left.\mathrm{H}_{2} \mathrm{O}_{2}=9\right)$. Reagents were added to perform the second stage and mixed for $120 \mathrm{~min}$; at the end of this time the effluent was filtered. The same procedure was followed for the third stage. The third stage effluent was adjusted to $\mathrm{pH} 7$ and filtered (Figure 1c). This final effluent was stored in the dark at $4{ }^{\circ} \mathrm{C}$ until analysis. The experiment was performed in triplicate, and data are expressed as mean values \pm standard deviation. In addition, an economic estimate was made to evaluate the benefits of applying reagents in three stages versus a single stage.

\section{Physicochemical characterization}

The physicochemical characteristics of SLL and treatment efficiency were evaluated by the following parameters: $\mathrm{pH}$, color, conductivity, COD, biological oxygen demand (BOD), biodegradability index (BI), total organic carbon (TOC), total solids (TS), total suspended solids (TSS), total dissolved solid (TDS), total phosphorous, total Kjeldahl nitrogen (TKN) and ammonia nitrogen $\left(\mathrm{N}-\mathrm{NH}_{3}\right)$, according to procedures recommended by the Standard Methods for the Examination of Water and Wastewater; ${ }^{24}$ residual $\mathrm{H}_{2} \mathrm{O}_{2}$ was tested using the iodometric titration method (Hach test kit, model HYP-1, Hach Company, CO, USA). To quantify the volume of sludge generated in this study treated SLL were put into measuring cylinders. After gravity settling for $60 \mathrm{~min}$, the volume of settled sludge was recorded. ${ }^{25}$

Metal(oid)s silver (Ag), aluminum (Al), arsenic (As), barium (Ba), cadmium $(\mathrm{Cd})$, cobalt $(\mathrm{Co})$, chromium $(\mathrm{Cr})$, iron $(\mathrm{Fe})$, nickel $(\mathrm{Ni})$,

(a)

(b)
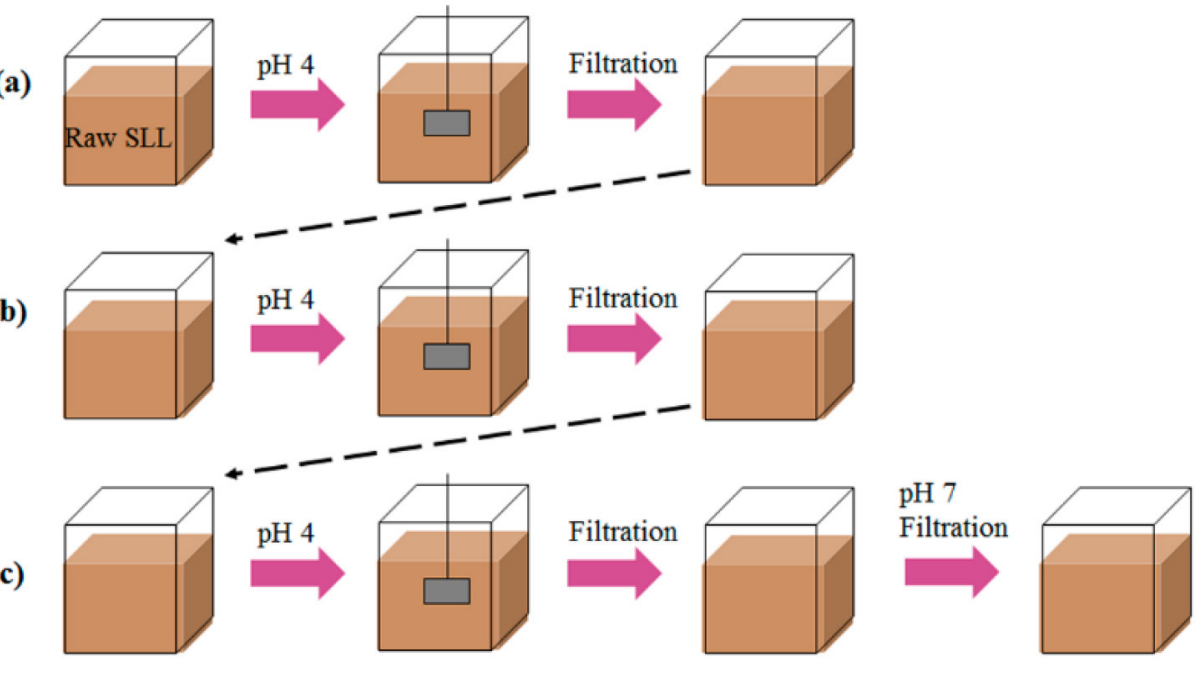

Influent

Fenton reaction

Effluent

Final effluent

Figure 1. Experimental setup of the triple-stage Fenton process: a) first stage, b) second stage and c) third stage. SSL: Sanitary landfill leachate 
lead $(\mathrm{Pb})$, vanadium $(\mathrm{V})$ and Zinc $(\mathrm{Zn})$ were determined following the USEPA method $3051 \mathrm{~A}^{26}$ using an inductively coupled plasma-mass spectrometer (ICP-MS, model iCapQ, Thermo Scientific, WI, USA).

\section{Chromatographic analysis}

For the detection of organic compounds, a gas chromatograph (GC, model Trace GC Ultra, Thermo Scientific, USA) coupled to a mass spectrometer was used (MS, model ITQ 900, Thermo Scientific, MA, USA). The samples were prepared before analysis according to the methodology described by Sang et al., ${ }^{27}$ with modifications implemented in the following way: the temperature program was set to increase from $50{ }^{\circ} \mathrm{C}$ (sustained for $1 \mathrm{~min}$ ) to $220^{\circ} \mathrm{C}$ (sustained for 2 min) with a $4{ }^{\circ} \mathrm{C} \mathrm{min}^{-1}$ ramp rate. The temperature was then increased to $300{ }^{\circ} \mathrm{C}$ (sustained for $1 \mathrm{~min}$ ) with a $5{ }^{\circ} \mathrm{C} \mathrm{min}^{-1}$ ramp rate. The injection volume was $1 \mu \mathrm{L}$ (splitless mode); the carrier gas was ultrahigh purity helium; and the stationary phase was a capillary column HP-5MS UI (Agilent/J\&W, CA, USA; $30 \mathrm{~m} \times 0.250 \mathrm{~mm} \times 0.25 \mu \mathrm{m}$ ). The mass spectrometer was used in the full scan mode $(50-450 \mathrm{~m} / \mathrm{z})$. All reagents were of high-performance liquid chromatography (HPLC) grade and obtained from JT Baker (Mallinckrodt Baker Inc, Edo de Mexico, Mexico).

\section{Toxicity tests}

The acute aquatic toxicity of the SLL before and after FP was determined by the $D$. magna test. To obtain reproducible and comparable results among different countries, standard test materials were used from the commercially available Daphtoxkit FTM Magna developed at the University of Ghent, Belgium. For sample concentration-response characterization, the evaluation parameter was the median effective concentration $\left(\mathrm{EC}_{50}\right)$. The entire procedure was carried out according to the user's manual. Briefly, the raw and treated SLL sample was prepared at five different concentrations $(3.125,6.25,12.5,25$ and 50\%) in standard freshwater for a range finding test. Undiluted raw and treated SLL (100\% concentration) were also included. Each concentration was tested with four replicates of five neonates $(<24 \mathrm{~h})$, together with a negative control. The temperature was controlled at $20 \pm 1{ }^{\circ} \mathrm{C}$. The number of immobilized and dead organisms for concentration was recorded after 48-h exposure. A second concentration series in the range of the lowest concentration that produced $100 \%$ lethality and the highest concentration that produced less than $10 \%$ lethality in the range finding test was prepared for a definitive test.

A quality control test was performed using as a reference chemical potassium dichromate $\left(\mathrm{K}_{2} \mathrm{Cr}_{2} \mathrm{O}_{7}\right)$ (Sigma-Aldrich, MO, USA), for which an acceptability range of $0.6-2.1 \mathrm{mg} \mathrm{L}^{-1}$ has been set in ISO standard 6341 for the $24 \mathrm{~h} \mathrm{EC}_{50}$ of the acute D. magna assay.

\section{Data analyses}

Analysis of variance via fixed effects and the method of least significant difference (LSD) were performed to contrast the means of each COD removal percentage using the InfoStat software version $2020 .{ }^{28}$ The same procedure was used to analyze the effect of raw and treated SSL on D. magna. The $\mathrm{EC}_{50}$ of D. magna was determined by Probit analysis using POLO Plus 2.0 statistical software. The significance in all statistical analyses was established at $\mathrm{p}<0.05$.

\section{RESULTS AND DISCUSSION}

\section{Physicochemical characterization}

The average results ( $n=3, \pm$ standard deviation) of the physicochemical characteristics on raw and treated SLL samples are presented in Table 1. Although raw SLL presented a high COD $\left(8925.00 \pm 65.00 \mathrm{mg} \mathrm{L}^{-1}\right)$, its low biodegradability index $\left(\mathrm{BOD}_{5} / \mathrm{COD}\right.$ ratio of $0.05 \pm 0.00)$, dark color $(14300.00 \pm 100.00 \mathrm{Pt}-\mathrm{Co}$ units $)$ and high $\mathrm{N}-\mathrm{NH}_{3}$ concentration $\left(649.67 \pm 10.02 \mathrm{mg} \mathrm{L}^{-1}\right)$ corresponded to a stabilized leachate. Hence, this sample should be efficiently treated with chemical process like Fenton oxidation rather than biological process. $^{10}$

The three successive stages of Fenton oxidation gradually reduced the COD content in SLL. After the first stage COD concentration was reduced from $8925.00 \pm 65.00$ to $2175.33 \pm 9.50 \mathrm{mg} \mathrm{L}^{-1}$ (Table 1) representing a removal efficiency of $76 \%$ (Figure 2). This result

Table 1. Comparison of physicochemical characteristics of raw and treated sanitary landfill leachate (SLL)

\begin{tabular}{|c|c|c|c|}
\hline \multirow{2}{*}{ Parameter } & \multirow{2}{*}{ Raw SLL } & \multicolumn{2}{|c|}{ Treated SLL } \\
\hline & & Single-stage FP & Triple-stage FP \\
\hline$\overline{\mathrm{pH}}$ & $8.43 \pm 0.06$ & $2.83 \pm 0.15$ & $7.00 \pm 0.10$ \\
\hline Color & $14300.00 \pm 100.00$ & $820.00 \pm 10.00$ & $1920.00 \pm 20.00$ \\
\hline Conductivity & $14406.67 \pm 37.86$ & $19638.67 \pm 67.72$ & $16930.00 \pm 10.00$ \\
\hline TOC & $2381.00 \pm 11.53$ & $480.33 \pm 13.05$ & $312.00 \pm 14.73$ \\
\hline $\mathrm{COD}$ & $8925.00 \pm 65.00$ & $2175.33 \pm 9.50$ & $1040.00 \pm 5.00$ \\
\hline $\mathrm{BOD}_{5}$ & $455.00 \pm 20.95$ & $210.00 \pm 10.00$ & $200.00 \pm 15.62$ \\
\hline $\mathrm{BI}\left(\mathrm{BOD}_{5} / \mathrm{COD}\right)$ & $0.05 \pm 0.00$ & $0.09 \pm 0.01$ & $0.19 \pm 0.01$ \\
\hline $\mathrm{TS}$ & $26392.00 \pm 151.80$ & $26033.33 \pm 208.17$ & $25380.00 \pm 201.76$ \\
\hline TSS & $520.00 \pm 20.00$ & $512.33 \pm 8.74$ & $511.33 \pm 16.04$ \\
\hline TDS & $25905.33 \pm 176.23$ & $25522.00 \pm 193.19$ & $24966.00 \pm 178.03$ \\
\hline TKN & $1099.56 \pm 16.66$ & $926.67 \pm 15.28$ & $816.34 \pm 16.66$ \\
\hline $\mathrm{N}-\mathrm{NH}_{3}$ & $649.67 \pm 10.02$ & $604.66 \pm 5.03$ & $599.00 \pm 8.54$ \\
\hline Total phosphorus & $41.80 \pm 0.80$ & $18.45 \pm 0.61$ & $8.60 \pm 0.56$ \\
\hline Residual $\mathrm{H}_{2} \mathrm{O}_{2}$ & - & $46.6 \pm 5.77$ & $20.00 \pm 0.00$ \\
\hline
\end{tabular}

All physicochemical parameters are presented in $\mathrm{mg} \mathrm{L}^{-1}$ except color $=$ Pt-Co Units, conductivity $=\mu \mathrm{S} \mathrm{cm}-1$; SLL: sanitary landfill leachate; FP: Fenton process; TOC: total organic carbon; COD: chemical oxygen demand; BOD: biochemical oxygen demand; BI: biodegradability index; TS: total solids; TSS: total suspended solids; TDS: total dissolved solids, TKN: total Kjeldahl nitrogen. 
coincided with that reported by San Pedro et al. ${ }^{29}$ who obtained $75 \%$ COD removal with a single-stage FP in this wastewater. Subsequently, the second stage contributed another 9\% (from $2175.33 \pm 9.50$ to $1373.33 \pm 11.55)$ COD removal, for an accumulated COD removal of $85 \%$ (Figure 2), while the third stage contributed 4\% COD removal (from $1373.33 \pm 11.55$ to $1040.00 \pm 5.00$ : Table 1 ), meaning that the overall COD removal was $88 \%$ (Figure 2). From these results, the triple-stage FP improved overall COD removal by $13 \%$ higher than a single-stage FP. This result was similar to Zhang et al. ${ }^{11}$ and Hermosilla et al., ${ }^{30}$ in which a $10 \%$ increase in COD removal was obtained when chemicals were added in a stepwise mode. A possible explanation for the superior COD removal is that more hydroxyl radicals could be generated improving the efficiency of the system. ${ }^{31}$

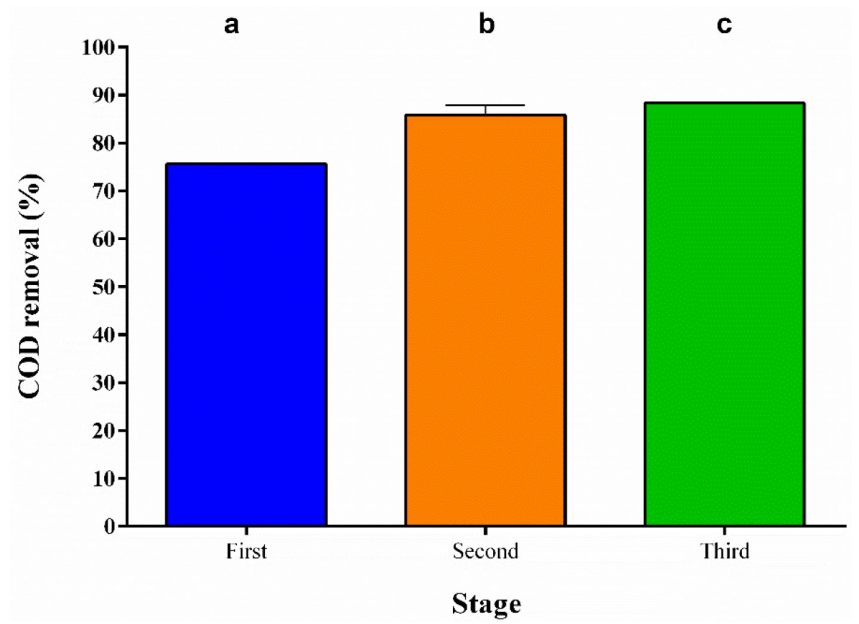

Figure 2. Accumulated chemical oxygen demand (COD) removal corresponding to each stage of Fenton process. Different letters indicate statistical differences $(p<0.05)$ according to an LSD test

\section{Economic analysis}

From economic perspective, triple stage FP did not mean a triplication of treatment costs. The second and third stage of FP reduced the reagents consumption and consequently sludge production. To compare the Fenton reagents usage, the first stage was taken as $100 \%$ chemical requirements (Figure 3 ). Acidification was only necessary in the first stage of the triple-stage FP since Fenton effluent was acidic in nature $(\approx \mathrm{pH} 2.8)$, while sodium hydroxide expenditure in second and third stage was minimal since a pH adjustment was needed from 2.8 to 4.0 (Table 1). The amounts of $\mathrm{Fe}_{2} \mathrm{SO}_{4} \cdot 7 \mathrm{H}_{2} \mathrm{O}$ and $\mathrm{H}_{2} \mathrm{O}_{2}$ required for the second $(\approx 24 \%)$ and the third stage $(\approx 12 \%)$ significantly decreased compared to the first stage because the chemical consumption was given by the remaining COD from influent (Figure 3). Liu et al. ${ }^{32}$ reported in a preliminary cost analysis that the major reagents cost for FP was for $\mathrm{H}_{2} \mathrm{O}_{2}$; therefore, despite of being a triple-stage treatment, the overall cost increased an estimate of $\approx 39 \%$ due to reagents requirements.

\section{Sludge formation}

With respect to sludge, although costs associated to disposal and handling of large amounts of ferric sludge generated from leachate Fenton treatments limit a more extended full-scale application, ${ }^{33}$ the two additional oxidation stages utilized in the present study produced low amounts of sludge (5.5\%). As shown in Figure 4, production of Fenton sludge was greatly reduced from $40 \%$ in volume in the first stage to $3 \%$ and $2.5 \%$ in the second and third stage, respectively.

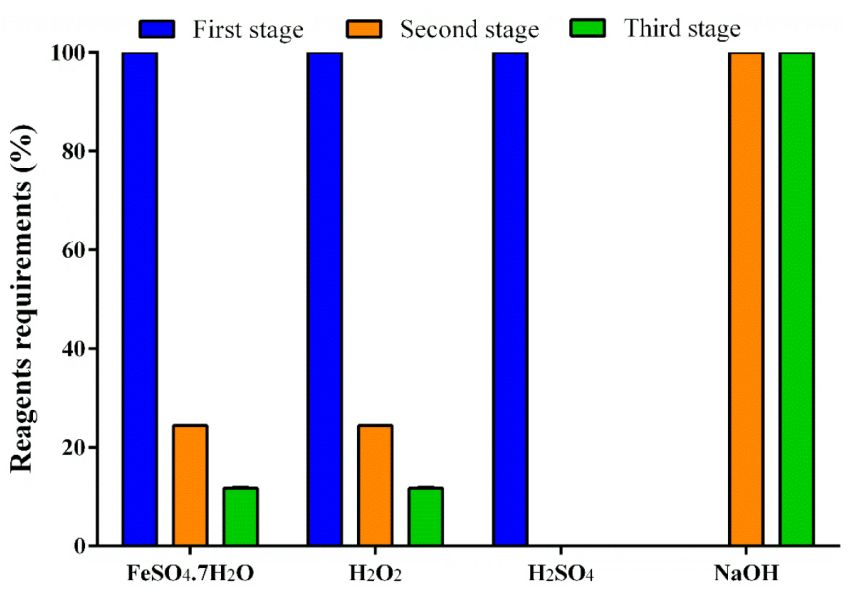

Figure 3. Comparison of reagents requirements among the three stages of Fenton process. $\mathrm{Fe}_{2} \mathrm{SO}_{4} \cdot 7 \mathrm{H}_{2} \mathrm{O}$ : ferrous sulfate heptahydrate; $\mathrm{H}_{2} \mathrm{O}_{2}$ : hydrogen peroxide; $\mathrm{H}_{2} \mathrm{SO}_{4}$ : sulfuric acid; $\mathrm{NaOH}$ : sodium hydroxide

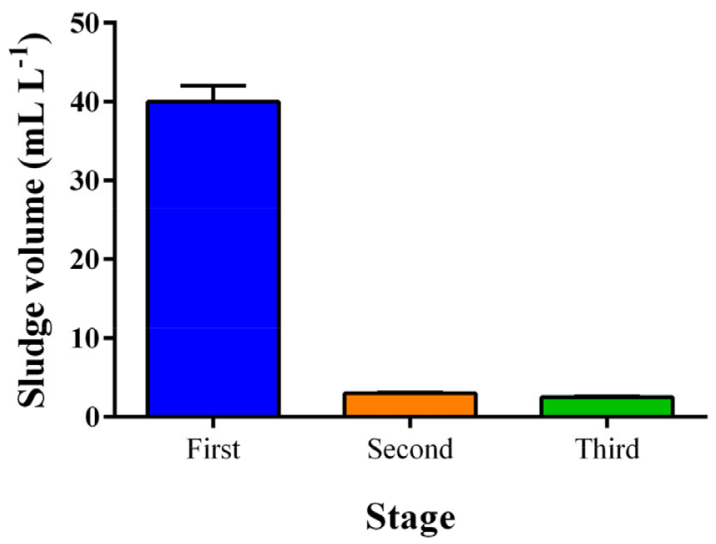

Figure 4. Sludge production in each stage of Fenton process

\section{Metal(oid)s concentrations}

Raw SLL contained detectable concentrations of $\mathrm{Ba}$ $\left(35.075 \pm 2.17 \mathrm{mg} \mathrm{L}^{-1}\right)>\mathrm{Zn}\left(18.796 \pm 4.74 \mathrm{mg} \mathrm{L}^{-1}\right)>\mathrm{Fe}$ $\left(13.860 \pm 0.21 \mathrm{mg} \mathrm{L}^{-1}\right)>\mathrm{Al}\left(7.228 \pm 1.77 \mathrm{mg} \mathrm{L}^{-1}\right)>\mathrm{Cr}$ $\left(1.961 \pm 0.04 \mathrm{mg} \mathrm{L}^{-1}\right)>\mathrm{Ni}\left(0.577 \pm 0.02 \mathrm{mg} \mathrm{L}^{-1}\right)>\mathrm{V}\left(0.354 \pm 0.01 \mathrm{mg} \mathrm{L}^{-1}\right)$ $>\mathrm{Co}\left(0.151 \pm 0.01 \mathrm{mg} \mathrm{L}^{-1}\right)>\mathrm{As}\left(0.110 \pm 0.00 \mathrm{mg} \mathrm{L}^{-1}\right)>$ $\mathrm{Pb}\left(0.074 \pm 0.04 \mathrm{mg} \mathrm{L}^{-1}\right)>\mathrm{Cd}\left(0.003 \pm 0.00 \mathrm{mg} \mathrm{L}^{-1}\right)>\mathrm{Ag}$ $\left(0.002 \pm 0.00 \mathrm{mg} \mathrm{L}^{-1}\right)$ (Table 2). Although most metal(oid)s in SLL are present in low concentrations due to adsorption, precipitation and complexation, ${ }^{34}$ its release to groundwater may potentially be of an environmental concern ${ }^{35}$ due to their toxicity and persistence. ${ }^{36}$ After applying the triple-stage FP, various metal(oid)s (such as V, $\mathrm{Cr}, \mathrm{As}, \mathrm{Al}, \mathrm{Ni}, \mathrm{Zn}$ and $\mathrm{Ba}$ ) were reduced in the treated SLL with removal percentages of $99 \%, 93 \%, 82 \%, 40 \%, 33 \%, 30 \%$ and $28 \%$, respectively (Table 2). For $\mathrm{Al}, \mathrm{As}, \mathrm{Cr}, \mathrm{Ni}$ and $\mathrm{V}$, concentrations similar to or below the concentrations permitted by international standards for safe discharge were achieved (Table 2). This decrement evidences the association between the removal of organic compounds and some metals. ${ }^{37}$ Although there is little information about the mechanism of the removal of metals, it seems that sludge sedimentation sweeps and removes heavy metals from a solution. ${ }^{38}$ In contrast, because iron is derived from the FP, its concentration in treated SLL substantially increased from $13.860 \pm 0.21$ to $146.467 \pm 5.29 \mathrm{mg} \mathrm{L}^{-1}$ (Table 2). Although iron is abundant in the Earth's crust and occurs naturally in the aquatic environment at levels ranging from 0.5 to $50 \mathrm{mg} \mathrm{L}^{-1},{ }^{39}$ iron removal should be conducted after the application of the FP in order to achieve international MPLs of iron in wastewater effluents. ${ }^{15}$ 
Table 2. Concentrations of metal(oid)s in raw and treated sanitary landfill leachate (SLL)

\begin{tabular}{|c|c|c|c|c|c|c|c|}
\hline \multirow{2}{*}{ Metal(oid)s } & \multirow{2}{*}{ Raw SLL } & \multirow{2}{*}{ Triple-stage FP } & \multirow{2}{*}{$\begin{array}{c}\text { Removal } \\
\text { efficiency }(\%)\end{array}$} & \multicolumn{4}{|c|}{ Standards limits for treated SLL } \\
\hline & & & & $\mathrm{WHO} / \mathrm{FAO}^{\mathrm{a}[42]}$ & $\mathrm{Oman}^{\mathrm{a}[43]}$ & Brazil $^{\mathrm{b}}[41]$ & WEPA $^{\mathrm{b}[40]}$ \\
\hline $\mathrm{Ag}$ & $0.002 \pm 0.00$ & $0.002 \pm 0.00$ & 3 & $*$ & 0.01 & 0.1 & 0.1 \\
\hline $\mathrm{Al}$ & $7.228 \pm 1.77$ & $4.355 \pm 1.30$ & 40 & 5.0 & 5.0 & $*$ & $*$ \\
\hline As & $0.110 \pm 0.00$ & $0.020 \pm 0.00$ & 82 & 0.1 & 0.1 & 0.5 & 0.25 \\
\hline $\mathrm{Ba}$ & $35.075 \pm 2.17$ & $25.387 \pm 5.21$ & 28 & $*$ & 1.0 & 5.0 & 1.0 \\
\hline $\mathrm{Cd}$ & $0.003 \pm 0.00$ & $0.002 \pm 0.00$ & 20 & 0.01 & 0.01 & 0.2 & 0.03 \\
\hline Co & $0.151 \pm 0.01$ & $0.120 \pm 0.01$ & 21 & 0.05 & 0.05 & $*$ & $*$ \\
\hline $\mathrm{Cr}$ & $1.961 \pm 0.04$ & $0.146 \pm 0.02$ & 93 & 0.1 & 0.05 & 0.1 & 0.5 \\
\hline $\mathrm{Ni}$ & $0.577 \pm 0.02$ & $0.386 \pm 0.04$ & 33 & 0.2 & 0.1 & 2.0 & 0.2 \\
\hline $\mathrm{Pb}$ & $0.074 \pm 0.04$ & ND & ND & 5.0 & 0.1 & 0.5 & 0.2 \\
\hline V & $0.354 \pm 0.01$ & $0.004 \pm 0.00$ & 99 & 0.1 & 0.1 & $*$ & $*$ \\
\hline $\mathrm{Zn}$ & $18.796 \pm 4.74$ & $13.070 \pm 2.29$ & 30 & 2.0 & 5.0 & 5.0 & 1.0 \\
\hline $\mathrm{Fe}$ & $13.860 \pm 0.21$ & $146.467 \pm 5.29$ & 0 & 5.0 & 1.0 & 15.0 & 2.0 \\
\hline
\end{tabular}

All values are presented in $\mathrm{mg} \mathrm{L}^{-1}$ except removal efficiencies (\%); SLL: sanitary landfill leachate; FP: Fenton process; WHO: World Health Organization; FAO: Food and Agriculture Organization; WEPA: Water Environment Partnership in Asia; ND: Non detected; * Not mentioned; ${ }^{\mathrm{a}}$ irrigation water; ${ }^{\mathrm{b}}$ discharging into water bodies and soil.

The Water Environment Partnership in Asia (WEPA) ${ }^{40}$ suggests the discharge limit for iron in general industrial wastewater is $2 \mathrm{mg} \mathrm{L}^{-1}$ while the Ministry of Environment of Brazil ${ }^{41}$ provides $15 \mathrm{mg} \mathrm{L}^{-1}$ as a MPL for iron discharging into water bodies. For wastewater reuse, FAO/WHO Guidelines ${ }^{42}$ for trace metals in irrigation water recommended a maximum concentration for iron of $5 \mathrm{mg} \mathrm{L}^{-1}$ while Omani Standard of Wastewater Reuse ${ }^{43}$ allowed $1 \mathrm{mg} \mathrm{L}^{-1}$ of iron for unrestricted irrigation (vegetables, uncooked crops, sports fields, and publics parks $)^{44}$ (Table 2$)$.

\section{Identification of organic compounds}

In the raw SLL, numerous peaks corresponding to a wide range of organic compounds were identified (Table 1S), most of them coming from natural sources such as plant and animal debris and microfauna; but, a xenobiotic of environmental concern, bisphenol A (BPA), was identified at 29.02 min retention time (RT) (Figure 5a; Table 1S). BPA is a common plasticizer used in the production of epoxy resins and polycarbonate which is a potential carcinogenic and endocrine disruptor. ${ }^{45} \mathrm{BPA}$ is frequently identified in sanitary SLL throughout the world. ${ }^{46}$ Regarding to treated SLL, although most of organic compounds identified in raw SLL were removed by FP, BPA compounds were refractory to oxidation. In this respect, BPA dimethacrylate was identified at $15 \mathrm{~min}$ of RT from the first stage effluent (Figure 5b, Table 1S), corroborating previous studies that reported that a single oxidation cycle was unable to destroy the structure of persistent organic pollutants such as BPA..$^{47}$ In addition, in the first stage effluent, pyridine, which is an endocrine disrupting chemical, ${ }^{46,47}$ was identified at $11.71 \mathrm{~min}$ of RT (Figure 5b, Table 1S).

In the effluents from second and third stage, BPA and pyridine were no longer identified (Figures $5 \mathrm{c}-\mathrm{d}$ ). Although new peaks were observed in each stage of FP (Figures 5b-d, Table S1), these peaks could be attributed to changes in relative abundances of the organic compounds. In the third stage effluent only two peaks were observed: acetamide (at $10.61 \mathrm{~min}$ of RT: Figure 5d) and cholestan-3-ol (at 13.04 min RT: Figure 5d). Acetamide is an ionic solvent and cholestan-3-ol is a faecal-derived sterol whose ecotoxicological risk for both compounds are insufficiently known..$^{48,49}$

\section{Toxicity of the leachate on D. magna}

As shown in Figure 6 there were significative differences in toxicity among raw and treated SSL. The toxicity test on D. magna revealed an $\mathrm{EC}_{50}$ of $6.63 \%$ for raw SLL (Figure $1 \mathrm{Sa}$ ). $\mathrm{EC}_{50}$ values $<9$ are classified as very toxic..$^{50}$ Even comparing this result with Dantas et al. ${ }^{10}$ who reported an $\mathrm{EC}_{50}$ of $12.49 \%$ in an old leachate from Paraiba, Brazil, the raw SLL was more toxic. However, after the triple-stage FP, the acute toxicity of treated SLL was reduced $64 \%$, attaining an $\mathrm{EC}_{50}$ of $18.62 \%$ (Figure 1Sb). By contrast, Dantas et al. ${ }^{14}$ found that effluent from an optimized FP increased toxicity, denoted by a change in the $\mathrm{EC}_{50}$ from $12.49 \%$ to $8.83 \%$. The increased toxicity of treated SLL could be attributed to the formation of Fenton reaction intermediates that were more toxic than the parent substances. Unlike this, the strategy used in the present study to improve the efficiency of the Fenton reaction significantly enhanced the removal of pollutants along with an increment in detoxification capacity. Although the effluents obtained from the triple-stage FP noticeable diminished its hazardousness, there was, however, residual toxicity to D. magna. To completely eliminate the toxicity of SLL after Fenton treatment possible toxic components including ammonia nitrogen, heavy metals, persistent organic pollutants, and treatment residuals may require the application of additional treatment units, such as membrane process or adsorption process..$^{51,52}$

\section{CONCLUSIONS}

In this study, the application of a triple-stage FP reduced concentrations of persistent contaminants and toxicity in recalcitrant SLL. This treatment achieved substantial removal of COD (88\%) and several metal(oid)s such as $\mathrm{Al}, \mathrm{As}, \mathrm{Ba}, \mathrm{Cr}, \mathrm{Ni}$ and $\mathrm{Zn}$. In addition, there was removal of organic compounds including BPA and a $64 \%$ reduction in toxicity to D. magna. In spite of the fact that triple-stage FP achieved a good effluent quality improvement, the resulting effluent was still toxic to living organisms indicating this treatment alone is not capable of full degradation of contaminants. However, triple-stage FP may provide a promising and viable alternative as pretreatment of SLL. These findings could contribute to the protection of Yucatán karst aquifer and public health. 

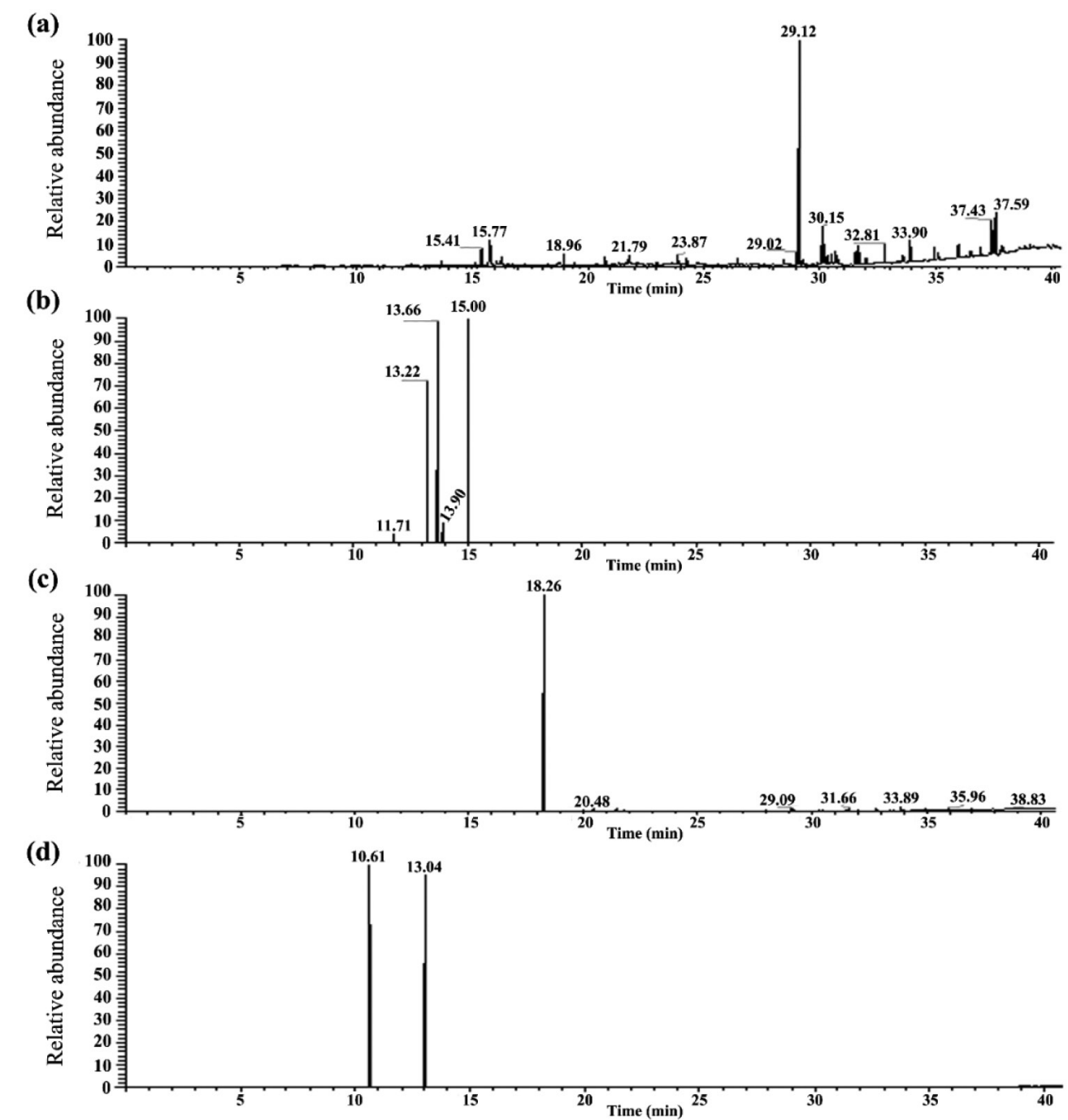

Figure 5. Total ion chromatogram. a) Raw sanitary landfill leachate, b) first stage of Fenton process, c) second stage of Fenton process and d) third stage of Fenton process

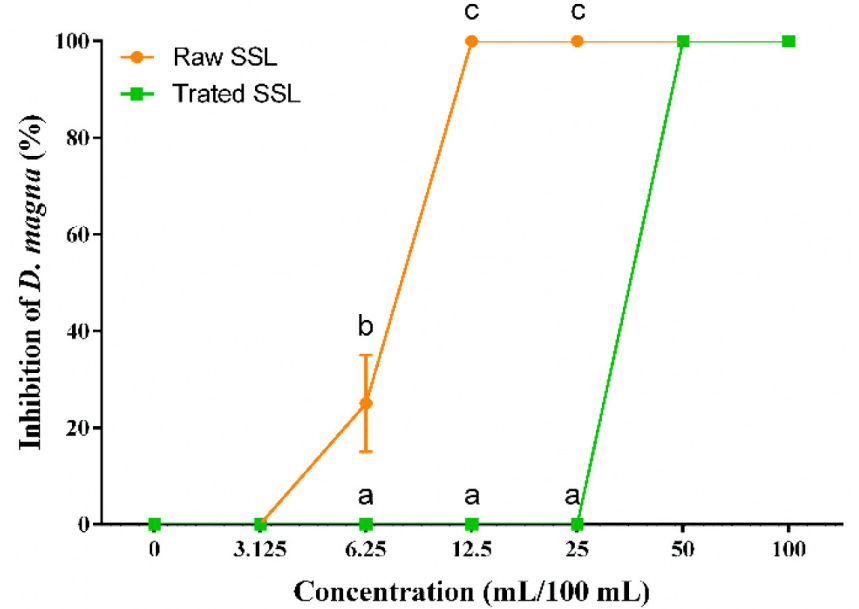

Figure 6. Percentage inhibition of Daphnia magna following 48 h exposure to dilution series of raw SLL and triple-stage Fenton process effluent (treated SLL) (Range finding test). SLL: Sanitary Landfill Leachate. Different letters indicate statistical differences $(p<0.05)$

\section{SUPPLEMENTARY MATERIAL}

Organic compounds detected on raw and Fenton treated sanitary landfill leachate (SLL) and the curve for $\mathrm{EC}_{50}-48$ in Daphnia magna are available on http://quimicanova.sbq.org.br in the form of a PDF file, with free access.

\section{ACKNOWLEDGEMENTS}

Thanks to the National Council for Science and Technology (CONACyT-Mexico) for scholarship funds (713025) to Ana M. Escalante-Mañe. We thank to Víctor Ceja-Moreno, Juvencio R. Pat-Canul, Mercedes A. Quintanilla-Mena, Luis A. Cetina-Euán, Isajav Rivas-Reyes, and Marcela Del Río-García for technical assistance.

\section{REFERENCES}

1. Bauer-Gottwein, P.; Gondwe, B. R. N.; Charvet, G.; Marín, L. E.; Rebolledo-Vieyra, M.; Merediz-Alonso, G.; Hydrogeol. J. 2011, $19,507$.

2. Goldscheider, N.; Chen, Z; Auler, A. S.; Bakalowicz, M.; Broda, S.; Drew, D.; Veni, G.; Hydrogeol. J. 2020, 28, 1661.

3. Luo, H.; Zeng, Y.; Cheng, Y.; He, D.; Pan, X.; Sci. Total Environ. 2020, 703,135468

4. Escalante-Mañe, A. M.; Hernández-Nuñez, E.; Méndez-Novelo, R. I.; Giácoman-Vallejos G.; González-Sánchez, A. A.; Quintanilla-Mena, M. A.; Puch-Hau, C.; Bull. Environ. Contam. Toxicol. 2021, 1. 
5. Xu, Y.; Xue, X.; Dong, L.; Nai, C.; Liu, Y.; Huang, Q.; Waste Manage. 2018, $82,156$.

6. Gama, M. R.; Rev. Virtual Quim. 2012, 4, 777.

7. Güneş, E.; Demir, E.; Güneş, Y.; Hanedar, A.; Sep. Purif. Technol. 2019, 209, 426.

8. Durai, N. J.; Gopalakrishna, G. V. T.; Padmanaban, V. C.; Selvaraju, N; RSC Adv. 2020, 10, 3916.

9. Lopez, A.; Pagano, M.; Volpe, A.; Di Pinto, A. C.; Chemosphere 2004, $54,1005$.

10. Deng, Y.; Englehardt, J. D.; Water Res. 2006, 40, 3683.

11. Zhang, H.; Choi, H. J.; Huang, C. P.; J. Hazard. Mater. 2005, 125, 166.

12. Yoo, H. C.; Cho, S. H.; Ko, S. O.; J. Environ. Sci. Health, Part A 2001, 36,39 .

13. Mahmud, K.; Hossain, M. D.; Ahmed, S.; Int. J. Environ. Sci. 2011, 2 , 259.

14. Dantas, E. R.; Silva, E. J.; Lopes, W. S.; do Nascimento, M. R.; Leite, V. D.; de Sousa, J. T.; Environ. Technol. 2020, 41, 2637.

15. Rueda-Márquez, J. J.; Levchuk, I.; Manzano, M.; Sillanpää, M.; Catalysts 2020, 10, 612.

16. Tkaczyk, A.; Bownik, A.; Dudka, J.; Kowal, K.; Ślaska, B.; Sci. Total Environ. 2020, 143038.

17. Sackey, L. N.; Kočí, V.; van Gestel, C. A.; Sci. Total Environ. 2020, 698 , 134295.

18. Organization for Economic Cooperation and Development, OECD; Test No. 202: Daphnia sp. acute immobilisation test. In OECD Guidelines for the Testing of Chemicals, Section 2; OECD Publishing: Paris, 2004.

19. Bownik, A.; Ślaska, B.; Dudka, J.; J. Hazard. Mater. 2020, 384, 121259.

20. Jonczyk, E.; Gilron, G. U. Y.; Acute and chronic toxicity testing with Daphnia sp. In Small-scale freshwater toxicity investigations; Blaise, C.; Férard, J. F., eds.; Springer Verlag: Netherlands, 2005, vol. 1, p. 337.

21. Guimarães, L.; Guilhermino, L.; Afonso, M. J.; Marques, J. M.; Chaminé, H. I.; Sustain. Water Resour. Manag. 2019, 5, 217.

22. Méndez-Novelo, R. I.; Pietrogiovanna-Bronca, J. A.; Santos-Ocampo, B.; Sauri-Riancho, M. R.; Giácoman-Vallejos, G.; Castillo-Borges, E. R.; Rev. Int. Contam. Ambiental 2010, 26, 211.

23. Colombo, A.; Módenes, A. N.; Trigueros, D. E.; de Medeiros, B. L.; Marin, P.; Monte Blanco, S. P.; Hinterholz, C. L.; J. Environ. Sci. Health, Part A 2019, 54, 269.

24. American Public Health Association, APHA; Standard Methods for the Examination of Water and Wastewater, $20^{\text {th }}$ ed., American Water Works Association and Water Pollution Control Federation: Washington DC, 2005.

25. Amiri, A.; Sabour, M. R.; Waste manage. 2014, 34, 2528.

26. Element, CAS; Zeitschrift für Analytische Chemie 2007, 111, 362.

27. Sang, Y. M.; Gu, Q. B.; Sun, T. C.; Li, F. S.; Water Sci. Technol. 2008, $58,1423$.

28. http://www.infostat.com.ar, accessed in February 2022.

29. San Pedro-Cedillo, L.; Méndez-Novelo, R. I.; Rojas-Valencia, M. N.; Barceló-Quintal, M; Castillo-Borges, E. R.; Sauri-Riancho, M. R.; Marrufo-Gómez, J. M.; Rev. Mex. Ing. Quím. 2015, 14, 745.
30. Hermosilla, D.; Cortijo, M.; Huang, C. P.; Sci. Total Environ. 2009, 407, 3473.

31. Carra, I.; Malato, S.; Jiménez, M.; Maldonado, M. I.; Pérez, JS; Chem. Eng. J. 2014, 235, 132.

32. Liu, X.; Novak, J. T.; He, Z.; Chemosphere 2020, 247, 125954.

33. Pliego, G.; Zazo, J. A.; Garcia-Muñoz, P.; Munoz, M.; Casas, J. A.; Rodriguez, J. J.; Crit. Rev. Environ. Sci. Technol. 2015, 45, 2611.

34. Xie, S.; Ma, Y.; Strong, P. J.; Clarke, W. P.; J. Hazard. Mater. 2015, 299, 577.

35. Varank, G.; Demir, A.; Top, S.; Sekman, E.; Akkaya, E.; Yetilmezsoy, K.; Bilgili, M. S.; Sci. Total Environ. 2011, 409, 3183.

36. Briffa, J.; Sinagra, E.; Blundell, R.; Heliyon 2020, 6, e04691.

37. Robinson, T.; Waste Manage. 2017, 63, 299.

38. Zazouli, M. A.; Yousefi, Z.; Eslami, A.; Ardebilian, M. B.; Iran. J. Environ. Health Sci. Eng. 2012, 9, 1.

39. World Health Organization, WHO; Guidelines for drinking-water quality: fourth edition incorporating the first addendum; WHO Press: Geneva, 2017. p. 381

40. http://www.wepa-db.net/policies/law/laos/standards.htm, accessed in February 2022.

41. Conselho Nacional do Meio Ambiente Resolução No 430. Dispõe Sobre as Condições e Padrões de Lançamento de Efluentes; Diário Oficial da União: Brasilia, Brasil, 2011.

42. World Health Organization/Food and Agriculture Organization, WHO/FAO. Guidelines for the safe use of wastewater and food stuff. Wastewater use in Agriculture, Report by WHO, Geneva, 2013, 2, 988.

43. Jaffar Abdul Khaliq, S.; Ahmed, M.; Al-Wardy, M.; Al-Busaidi, A.; Choudri, B. S.; J. Air Waste Manage. Assoc. 2017, 67, 267.

44. Al-Musharafi, S. K.; Mahmoud, I. Y.; Al-Bahry, S. N.; APCBEE Proc. 2013, 5, 344.

45. Kim, H.; Yim, B.; Bae, C.; Lee, Y. M.; Toxicol. Environ. Health Sci. 2017, 9, 41.

46. Seibert, D.; Quesada, H.; Bergamasco, R.; Borba, F. H.; Pellenz, L.; Process Saf. Environ. Prot. 2019, 131, 255

47. Ramírez-Sosa, D. R.; Castillo-Borges, E. R.; Méndez-Novelo, R. I.; Sauri-Riancho, M. R.; Barceló-Quintal, M.; Marrufo-Gómez, J. M.; Waste Manage. 2013, 33, 390.

48. Wen, Q.; Chen, J. X.; Tang, Y. L.; Wang, J.; Yang, Z.; Chemosphere 2015, 132, 63.

49. González-Acevedo, Z. I.; García-Zarate, M. A.; Flores-Lugo, I. P.; Environ. Pollut. 2019, 244, 885.

50. Barrios-Restrepo, J. J.; Flohr, L; Melegari, S. P.; da Costa, C. H.; Fuzinatto, C. F.; de Castilhos Jr., A. B.; Matias, W. G.; Environ. Technol. 2017, 38, 2898 .

51. Wang, J.; Wang, S.; J. Cleaner Prod. 2021, 128202.

52. San-Pedro, L.; Méndez-Novelo, R.; Hernández-Núñez, E.; NájeraAguilar, H. A.; Gutiérrez-Hernández, R. F.; Rev. Mex. Ing. Quim. 2021, 20,853 . 